\title{
LAS DEFICIENCIAS ESTRUCTURALES Y PRÁCTICAS DE LA ACCIÓN DE PROTECCIÓN*
}

\author{
KAMEl CaZor Aliste ${ }^{* *}$ \\ CHRISTIAN Rojas CALDERóN ${ }^{* * *}$
}

\begin{abstract}
RESUMEN: Los autores abordan las principales caracteristicas desde una visión histórico-jurídica de este instituto, para luego analizar el marco regulatorio de esta acción constitucional con el objeto de encontrar las deficiencias estructurales, cuestión que tiene claras consecuencias en su cometido primordial, cual es, desplegar la tutela judicial oportuna y efectiva frente al agravio de un derecho fundamental amparado.
\end{abstract}

PALABRAS CLAVE: Derechos - protección - acción - admisibilidad debido proceso.

\section{STRUCTURAL AND PRACTICAL DEFICIENCIES OF THE ACTION OF PROTECTION}

ABSTRACT: The authors deal with the main characteristics of this constitutional action, from a legal-historical point of view of this Institute. They later analyze its regulatory framework in order to find the structural deficiencies, which have clear consequences in its main purpose, this is, to display its judicial tutelage in a timely and effective manner in the face of a tort of a protected fundamental right.

KEY WORDS: Rights - protection - action - admissibility - due process.

\footnotetext{
* El presente trabajo forma parte del proyecto de investigación DGIP-UnIVERsidad CatóliCA DEL NORTE No 0520101-10301199, del cual sus autores son investigadores responsables. Los cuales, además, quieren dejar constancia de la valiosa colaboración de la ayudante de Derecho Constitucional dońa Katherine Becerra Valdivia, en la recopilación de los datos jurisprudenciales aquí presentados.

* Licenciado en Ciencias Jurídicas, Universidad Central de Chile. Doctor en Derecho, Universidad de Valladolid (España). Profesor de Derecho Constitucional en la Universidad Católica del Norte (CHILE). Correo electrónico: cazor@ucn.cl.

*** Licenciado en Ciencias Jurídicas, Universidad de Valparaíso. Magíster en Ciencia Jurídica, P. Universidad Católica de Chile. Profesor de Derecho Administrativo en la Universidad Católica del Norte (CHILE). Correo electrónico: chrojas@ucn.cl Fecha de recepción: 30 de abril de 2009.

Fecha de aceptación: 6 de julio de 2009.
} 


\section{CONTEXTO DE LA INDAGACIÓN}

En el presente artículo se abordarán las principales deficiencias estructurales y prácticas que es posible constatar en la acción constitucional de protección, cuestión que tiene claras consecuencias en el cometido primordial que la sustenta, cual es, desplegar la tutela judicial oportuna y efectiva frente al agravio de un derecho fundamental amparado. De esto es posible constatar, por una parte - desde una perspectiva de forma-, una costumbre sostenida de denegación de justicia de los órganos jurisdiccionales de protección cuando no admiten a tramitación esta acción; o, por la otra -ahora desde una perspectiva de fondo-, una respuesta insuficiente si consideramos, la mayoría de las veces, la escasa motivación constitucional en la ratio decidendi de la sentencia, esto es, alejada de la perspectiva constitucional que debe sustentar su razonamiento jurisdiccional. Todo lo cual, sin lugar a dudas, afecta la conceptualización y práctica de los derechos fundamentales en nuestro país, repercutiendo en la innegable dimensión pública que posee la acción de protección al tutelar tales derechos subjetivos.

Conviene recordar, en este tema, que la expresión "garantías de los derechos fundamentales" carece de un significado técnico-jurídico preciso, ya que hace referencia al conjunto de medios que el ordenamiento prevé para la protección, tutela o salvaguardia de los derechos fundamentales. Se trata de un conjunto heterogéneo, pues abarca tanto procedimientos de distinta índole como requisitos sustantivos, cuyo rasgo común es precisamente la de estar dirigidos a asegurar la observancia y la efectividad de las garantías constitucionales. Si nos situamos en la esfera de la acción de protección, en el artículo 20 de la Carta, como bien es sabido, se enumeran taxativamente los derechos fundamentales tutelados y los presupuestos procesales básicos para su interposición, cuyo procedimiento además está regulado en el Auto Acordado de la Corte Suprema. Por esta razón, a fin de abordar esta acción constitucional, el análisis en cuestión no podría separar, a nuestro parecer, la sustancialidad de los derechos garantizados de sus presupuestos procedimentales, toda vez que, como se verá más adelante, su telos se debe enmarcar dentro de una genuina jurisdicción constitucional de los derechos fundamentales.

A fin de desarrollar nuestra reflexión, dividiremos la indagación desde dos perspectivas: en primer término, se abordará lo concerniente a la protección de los derechos de las personas desde una visión histórico-jurídica; $y$, en segundo lugar, se hará frente -críticamente- al actual marco regulatorio de esta acción constitucional.

Finalmente, recogeremos una conclusión general de este trabajo, cuyo principal objetivo es divulgar, en una proyección práctica, la escasa operatividad y repercusión en la esfera de los derechos fundamentales de este instituto procesal. 


\section{1) LA PROTECCIÓN DE LOS DERECHOS DE LAS PERSONAS. UNA REVI- SIÓN HISTÓRICO-JURÍDICA}

\section{(1.1) Generalidades}

Constituye una destacada nota característica de la historia jurídica hispano-indiana, la existencia de un complejo régimen de control jurisdiccional de los actos gubernativos. Aquello, por cierto, ya se ha destacado con anterioridad de manera muy documentada ${ }^{1}$.

Ahora bien, en cada uno de esos casos se dejó igualmente en claro que la protección de los derechos de las personas no es un fenómeno propio del constitucionalismo, sino que probablemente a partir de este original sistema ${ }^{2}$, se reencausó hasta su actual configuración. En ese camino, sin embargo, no siempre se ha acertado, como se pondrá de manifiesto más adelante.

Tal como expresa Herrera Valverde, la apelación contra actos gubernativos fue el mejor remedio para obtener la protección de la persona y sus bienes, por parte de la institucionalidad debidamente resguardada por la Real Audiencia.

Luego, las cuestiones suscitadas a propósito de la protección de las persona y sus bienes -derechos diríamos hoy-en términos muy amplios se puede calificar como una situación propiamente contencioso-administrativo a la que debe vincularse un sistema jurídico regulatorio de esas situaciones, destinado fundamentalmente a la protección de los particulares. En el supuesto de la existencia de ese sistema, puede configurárselo como una vía de garantías que el Estado otorga a los particulares en sus relaciones con la Administración Pública y que se traduciría en la pretensión procesal de un ciudadano en contra de la misma, que deberá ser conocida por un tribunal a consecuencia de la violación de un derecho o de un interés legítimo. Este contencioso especial surge del carácter público de una de las partes; de la rama del Derecho aplicable; de la especialidad del juez que conoce; y de la trascendencia del resultado para la colectividad.

Sánchez BelLa, I. (1979). "Las Audiencias y el Gobierno de las Indias (siglos XVI y XVII). REH-J, No 2, pp. 159-186; Bravo Lira, B. (1989). "Protección jurídica de los gobernados en el Nuevo mundo (1492-1992). Del absolutismo al constitucionalismo". RCHHD, No XVI, pp. 315-349; Barrientos Grandón, J. (1992-1993). "La fiscalización de los actos de gobierno en le época indiana y su desaparición durante la República", REH-J, XV, pp. 103130; y Herrera Valverde, J. (2007). "El control jurisdiccional de los actos gubernativos en indias en los siglos XVI y XVII". Ius Publicum No 18, pp. 23-35.

2 En el que hay que destacar los contenciosos - que con lenguaje contemporáneo-, podríamos denominar de "administrativos", siguientes: visitas de la tierra, juicio de residencia, suspensión de ley injusta, recurso de nulidad, casos de corte, recurso de apelación, y recurso de suplicación y segunda suplicación. 


\section{(1.2) SOBRE EL SUPUESTO EXCLUSIVO ORIGEN FRANCÉS O ANGLOAME- RICANO DE LA PROTECCIÓN DE DERECHOS}

Constituye casi un lugar común decir que el principio de legalidad de la acción de los poderes públicos, y el principio de la libertad fueron introducidos al pensamiento político occidental por la Revolución France$\mathrm{sa}^{3}$. A estos dos principios se contrapone el concepto de "acto arbitrario" particularmente de la Administración, situación a la que debía buscársele una respuesta dada la vulneración producida a partir de esta.

Asimismo, también es lugar común decir que los sistemas de control de los actos arbitrarios del poder público se han dividido en zonas de influencia por el Derecho francés y el Derecho angloamericano. Así incluso, luego de exponer las características de los mencionados ordenamientos y de frente a la protección de los derechos de las personas, Fiamma sostiene que en Chile existe un régimen de protección de los derechos de las personas de carácter mixto (un "régimen administrativo tutelado"), dado que en este confluyen características tanto del sistema francés como del angloamericano ${ }^{4}$.

No obstante dicha opinión común, hay que señalar que la justicia administrativa no nació con la Revolución Francesa ${ }^{5}$, ni con los ideales independentistas americanos de 1776 sino que es mucho más antigua como ya se adelantara y se asentará a continuación.

\section{(1.3) SOBRE EL ORIGEN HISPANOAMERICANO DE PROTECCIÓN DE LAS PERSONAS RESPECTO DE ACTOS DE LA AUTORIDAD}

Ya en la obra de García de Enterría y Fernández que se citara, se hace referencia a que la protección judicialista de los derechos de las personas en Espańa tiene algún antecedente invocable respecto del "antiguo Derecho" 6 .

García de Enterría, E. y Fernández, T.-R. (2001). Curso de Derecho Administrativo. Tomo II. Madrid: Civitas, pp. 556-558.

4 Sostiene Fiamma que el sistema chileno, en términos generales, se podría caracterizar por consagrar el principio se separación de funciones al igual que lo hace el sistema inglés, es decir, relativamente; y el principio de igualdad ante la ley, al igual que el modelo francés, es decir de una manera no absoluta. De lo que se sigue que al regular ambos principios, el de igualdad y el de separación, de un modo relativo, el sistema chileno se aparta tanto del sistema inglés como del francés, dando lugar a un sistema distinto que podríamos denominar un régimen administrativo tutelado. Fiamma Olivares, G. (1986). "El régimen administrativo tutelado". Gaceta Juridica, No 71, pp. 7-10.

5 Lo mismo dice y fundamenta Cassagne, J. C. (2005a). "Consideraciones sobre la justicia administrativa en Argentina y en otros países de iberoamérica". En González Pérez, J. y Cassagne, J. C. La justicia administrativa en Iberoamérica. Buenos Aires: LexisNexis Argentina, pp. 38-40.

6 García de Enterría y Fernández (2001) 558. 
Sabido es, por otro lado, que la jurisdicción debe ser entendida como originaria del poder real derivado de la autoridad que tiene alguno para gobernar y poner en ejecución las leyes, y especialmente la potestad de que se hayan investidos los jueces como derivación de dicho poder soberano para administrar justicia.

Precisamente en este "antiguo Derecho", que es principalmente el medieval espańol (de Castilla) y por ende aplicado en Indias, "gobernar" se entendía como regir ampliamente, o sea mantener a los vasallos en paz y justicia; ampararlos en la paz y en la guerra; proteger a la Iglesia; y, en los reinos americanos, apoyar su labor evangelizadora ${ }^{7}$. Luego, la Judicatura resulta ser una manifestación del poder del soberano, del mismo modo que la Hacienda, el Ejército, y el Gobierno Interior.

Como se ha dicho, las circunstancias particulares de la lejanía del centro del poder real respecto de América, determinó efectivamente que la competencia a gravamine -o sea, la que conoce de los agravios causados contra vasallos del rey, por agentes del rey o por él mismo-, fuera la que se desarrollara de mejor forma, y más extensivamente ${ }^{8}$. En efecto, el remedio más eficaz para dar solución a los vasallos de los abusos ocurridos por actos de gobierno, no eran los recursos así utilizados en Castilla, sino que unos y otros se fueron transformando a fin de adecuarse a las circunstancias. Esta judicatura se relacionaba directamente con el ejercicio de los reclamos por vía de apelación gubernativa que los vasallos realizaban ante las audiencias en materias de gobierno, cuando una decisión de dicha clase producía agravio a una persona, de frente a la actuación de los gobernantes ${ }^{9}$. Lo anterior ocurrió, a lo menos, desde la instalación de la Real Audiencia en Santiago hacia el año $1609^{10}$.

De esta forma, sin dejar de ser un tribunal que se encarga de ver materias civiles y criminales, importante labor es precisamente la de ver cuestiones de esta competencia, protegiendo a los vasallos de los excesos de los gobernantes ${ }^{11}$. Así, la competencia en materia de protección de derechos de las personas se presenta como la más importante de entre aquellas que cumple la judicatura. Y esto provenía de la rica tradición hispánica y por consiguiente indiana, de brindar medios concretos de protección o seguridades personales, no a derechos, sino inmediatamente sobre los bienes; por consiguiente recaen no sobre el derecho a la vida, el derecho a la libertad o el derecho de propiedad, sino que directamente sobre la vida,

\footnotetext{
7

De lo cual deriva la distinción sustancial existente entre la labor colonizadora realizada por los países europeos y la incursión fundacional hispana y portuguesa.

8 Bravo Lira, B. (1996). Por la razón o la fuerza. El Estado de Derecho en la Historia de Chile. Santiago: Ediciones Universidad Católica de Chile, pp. 143-146.

BARRIENTOS (1992-1993) 105-107.

10 Existió, como se sabe, una anterior que funcionó en Concepción entre 1567 a 1575.

11 Recuérdese a estos efectos la frase "Viva el rey, muera el mal gobierno", que es indiciaria de la conciencia del vasallo, respecto de quien finalmente es el que rige.
} 
la libertad y la propiedad. Ellos encuentran sus antecedentes en los Concilios toledanos de 636 y 683 y especialmente en la Carta Magna Leonesa de 1188, los fueros locales desde el siglo X, las Partidas y en las Leyes de Indias ${ }^{12}$.

Se manifiesta, de este modo, la diferencia con los derechos subjetivos anglosajones y las declaraciones de derechos humanos francesa y estadounidense que, a fin de cuentas, resultan ser meras abstracciones.

\section{(1.4) LA PROTECCIÓN DE LOS DERECHOS DE LAS PERSONAS EN EL CHILE REPUblicano}

No obstante lo seńalado, a partir de la segunda mitad del siglo XVIII, con la ampliación de las materias de gobierno llevadas a cabo por las reformas monárquicas impulsadas por el ideal del absolutismo ilustrado, las materias de justicia referidas precedentemente se redujeron. Ello tuvo el necesario complemento con la posterior irrupción del constitucionalismo, y la aplicación muy estricta de la separación de poderes, en cuya virtud, las materias de justicia se condujeron al proceso destinado al asentamiento de, cada vez, más reducidas competencias de la judicatura; particularmente respecto de causas civiles y criminales.

Sin embargo, la tradición ya indicada, hizo que se mantuvieran estos resguardos o protecciones. Esto ha sido destacado también por Cassag$n e^{13}$, quien encuentra en la Constitución liberal de Cádiz de $1812^{14}$, un claro fundamento de la interdicción del ejercicio de funciones judiciales por el poder ejecutivo -como Gobernantes o Administración- que comenzaba a delimitarse en ese tiempo, y que es consecuencia precisa del sistema judicialista hispanoamericano, traducido en un poder judicial independiente originado en el Derecho aragonés ${ }^{15}$, y no del constitucionalismo aunque renovado o redireccionado por este.

Así, hay un desarrollo normativo sin solución de continuidad en esta materia de resguardo de derechos de los individuos.

$Y$ ello encuentra su asentamiento en que con posterioridad a la independencia definitiva de Chile, asentándose como una república y hasta 1823 -en que se funda la Corte Suprema- subsistió el orden judicial

Bravo Lira, B. (1986). "Derechos políticos y civiles en España, Portugal y América Hispana. Apuntes para una historia por hacer". Revista de Derecho Público Nos. 39-40, pp. 73-77. CASSAGNE, J.C. (2005b). "El origen hispánico del sistema judicialista y de otras instituciones del Derecho público iberoamericano y comparado", En González Pérez, J. y Cassagne, J.C. (2005). La justicia administrativa en Iberoamérica. Buenos Aires: LexisNexis Argentina, pp. 11-29.

I4 Particularmente en su artículo 243 que dispone "Ni las Cortes ni el Rey podrán ejercer en ningún caso las funciones judiciales, avocar causas pendientes, ni mandar a abrir los juicios fenecidos"; que tiene su expresión en nuestro actual artículo 76 de la CPR. En el llamado "Justicia de Aragón". 
anterior. A partir de dicho año, en que se dictó la Constitución Política y Permanente del Estado -producto del trabajo realizado fundamentalmente por Juan Egańa-, se establece como la primera magistratura judicial del Estado a la Suprema Corte de Justicia ${ }^{16}$. Particularmente el artículo 116 de dicho texto establecía que el "Poder Judicial protege los derechos individuales" y el artículo 146 que indica las atribuciones particulares de la Corte Suprema le atribuye a ella, en primer lugar, la competencia para "proteger, hacer cumplir y reclamar a los otros poderes por las garantías individuales y judiciales". Sin embargo, como explica abundantemente Bravo Lira, esta fue inoperante las más de las veces, no pudiendo resguardar los derechos de las personas, sobre todo de frente a la violencia de los gobernantes $^{17}$.

Luego, producto de una reforma producida por una ley de 1835 , aparece una Corte Suprema renovada y más operativa en relación a la posibilidad que esta tenía de reclamar a los otros poderes del Estado el respeto por las garantías individuales; lo que sin duda tuvo un serio revés al dictarse en 1875 la Ley de organización y atribuciones de los tribunales donde se cercena dicha facultad al máximo tribunal, dejando las más de las veces indefensos a los particulares ante el ejercicio del poder por los gobernantes, centrándose en sus competencias de apelación y luego de casación $^{18}$.

Así, desde mediados del siglo XIX y hasta bien entrado el siglo XX, aun cuando el ejercicio del poder se fundaba en ideales libertarios e independentistas, las actuaciones del gobierno fueron realizadas prácticamente en impunidad, dado que los reclamos que se realizan de frente a la Administración eran resueltas por ella misma. En efecto, ténganse en cuenta los Tribunales de Aduana, el Director Regional del Servicio de Impuestos Internos, entre otros tantos órganos de la administración central a quienes se traspasó la competencia a gravamine, o por abusos de interés o derechos, al instaurarse la república. Sin embargo, los tribunales siguieron conociendo en algunos casos de las cuestiones vinculadas esencialmente a la protección de los derechos de los particulares afectados por acciones de autoridades administrativas.

\footnotetext{
16 Instalada el 19 de diciembre de 1823.

17 Bravo Lira, B. (2006). El Juez entre el Derecho y la Ley: Estado de Derecho y Derecho del Estado en el mundo hispánico, siglos XVI a XXI. Santiago: LexisNexis, pp. 623-628.

18 Como señalan Ferrada, Bordalí y Cazor, las potestades en tal sentido se establecieron en la Constitución de 1823, fueron recogidas en los reglamentos judiciales de 1824 y 1836 y rigieron hasta 1875 siendo suprimida por la ley de ese año ya seńalada (aunque existían otros mecanismos que prácticamente no fueron operativos, como la Comisión Conservadora). FErrada Bórquez, J.C. / Bordalí Salamanca, A. / Cazor Aliste, K. (2003). "El recurso de protección como mecanismo de control jurisdiccional ordinario de los actos administrativos: una respuesta inapropiada a un problema jurídico complejo". Revista de Derecho Universidad Austral de Chile. Vol. XIV, pp. 69-70.
} 
A mayor abundamiento del cercenamiento ya señalado, como señala Soto Kloss y refiriéndose a la misma época, comenzó a prosperar en las decisiones jurisprudenciales del máximo tribunal la idea consistente en que los tribunales ordinarios no serían competentes para conocer de la impugnación de los actos de la Administración, ya que emanaban de las atribuciones que la Constitución y la Ley le otorgan al Presidente de la República. Lo anterior se vio reforzado con la dictación de la Constitución de 1925 que en su artículo 87 establecía los tribunales administrativos como competentes para conocer de dichas situaciones ${ }^{19}$. Como bien se sabe, nunca se dictó la ley respectiva para crearlos y ponerlos en funcionamiento.

A pesar de lo dicho, algunos -como Tavolari ${ }^{20}$ - sostienen que las así llamadas facultades conservadoras del actual artículo $3^{\circ}$ del Código Orgánico de Tribunales, de larga data y antecedentes en nuestro Derecho, velarían por las garantías individuales. Sin embargo, del desarrollo legislativo parece que aquello ocurre tan solo con algunas garantías, particularmente las relativas a la vida y la libertad -protegidas por el habeas corpus-, pero no así respecto de los demás derechos fundamentales.

Nada de la situación antedicha cambiaría, salvo honrosas excepciones jurisprudenciales y la protección prodigada a través del amparo específico, hasta la creación en 1976 del llamado Recurso de Protección de Garantías Constitucionales $^{21}$.

Como bien se sabe, este "recurso de protección" fue incorporado a nuestro ordenamiento en el artículo $2^{\circ}$ del Acta Constitucional № 3 de Derechos y Deberes Constitucionales, y su objetivo era crear un instrumento ágil y expedito para la protección de los derechos fundamentales especialmente los de orden patrimonial ${ }^{22}$. Solo a partir de este se recupera la triple competencia: civil, criminal y a gravamine ${ }^{23}$; y con ello se avanza en la instauración de controles más efectivos ante vulneraciones de derechos fundamentales, particularmente de aquellos cometidos por la acción de la Administración. Sin embargo, esta circunstancia ha traído como

Soto Kloss, E. (2003). "La protección de los derechos de las personas, logros y penurias". Ius Publicum No 10 , pp. 73-75.

20 Donde realiza una revisión histórico-legislativa de la protección de las garantías individuales reconociendo seis períodos: 1810 a 1833,1833 a 1875,1875 a 1906,1906 a 1973,1973 a 1990 y 1990 en adelante. Tavolari Oliveros, R. (1994). "Hacia la tutela eficaz de los derechos humanos por la jurisdicción: una perspectiva desde el Derecho chileno referida al habeas corpus". En Él mismo. Tribunales, jurisdicción y proceso. Santiago: Editorial Jurídica de Chile, pp. 171-186.

21 En diciembre de 1972 los parlamentarios Sergio Díez y Mario Arnello propusieron ampliar la competencia del habeas corpus, reviviendo la apelación contra actos de gobierno indiano, to que tendría sus frutos cuatro años después con el recurso de protección. Bravo (2006) 640. Soto Kloss, E. (1982). El recurso de protección. Doctrina, orígenes y jurisprudencia. Santiago: Editorial Jurídica de Chile, pp. 23-26. 
consecuencia que la acción constitucional de protección, en la práctica, haya suplido la falta de una jurisdicción especializada en lo contencioso administrativo; y como lo hemos mencionado en otra parte, "transformándose en una acción -teóricamente extraordinaria-de ordinaria ocurrencia en la esfera del control de la Administración" ${ }^{24}$, perspectiva que ha expandido la jurisdicción de protección, entre otros asuntos, al conocimiento de cuestiones que no son estrictamente de derechos fundamentales (derechos subjetivos o intereses legítimos no fundamentales), como asimismo a la resolución de temáticas que deben ser resueltas en un juicio de lato conocimiento.

\section{2) ACTUAL MARCO REGULATORIO DE LA ACCIÓN DE PROTECCIÓN DE LOS DERECHOS FUNDAMENTALES. ANÁLISIS CRÍTICO}

\section{(2.1) CONSIDERACIONES GENERALES}

Como señala Carrasco, "la línea histórica de evolución del constitucionalismo viene marcada por el creciente arraigo de los derechos humanos dentro de los textos constitucionales" 25 , pero al mismo tiempo cabe señalar que eso no basta pues dichos derechos no solo deben estar presentes en los textos sino ser eficaces "al punto de que puede decirse que no hay derechos fundamentales si no hay garantía jurisdiccional de los mismos" 26 . Precisamente eso es lo que se realiza o materializa con la provisión de instrumentos que restablezcan o preserven las situaciones jurídicas subjetivas de los particulares, que se encuentran afectadas por actos realizados por poderes públicos $\mathrm{u}$ otros privados contraria a los términos del reconocimiento normativo-constitucional de estos derechos. Esa es precisamente la tarea entregada al denominado Recurso de Protección.

Como bien se sabe, los contornos regulatorios del "recurso de protección”, están determinados por una disposición constitucional (el artículo 20) y por el Auto Acordado de la Corte Suprema sobre tramitación del Recurso de Protección de Garantías Constitucionales, de 27 de junio de 1992 (modificado por Auto Acordado de la misma Corte de 25 de mayo de 2007). Sobre el particular, igualmente, hay que hacer mención que en el año 2007 se actualizó y perfeccionó el proyecto de ley sobre "acciones constitucionales de amparo o hábeas corpus y de protección", que en su nueva versión se titula "proyecto de ley de acciones protectoras de dere-

\footnotetext{
24 Cazor, K. (2002). La sumisión a Derecho de los actos y disposiciones del Presidente de la República. Tomo II. Santiago: Universidad Central de Chile, p. 304.

25 Carrasco Durán, M. (2002). Los procesos para la tutela jurisdiccional de los derechos fundamentales. Madrid: Centro de Estudios Políticos y Constitucionales, p. 29.

26 CARrasco (2002) 34
} 
chos fundamentales", en trámite en la Cámara de Diputados (Boletín № 2809-07), y que regula un conjunto de garantías jurisdiccionales -constitucionales y legales- de derechos fundamentales, asegurados en la Constitución y en los tratados internacionales en vigor, dentro de las cuales se encuentra la acción de protección.

Dentro de este contexto, a fin de abordar la acción de protección en este acápite y como ya se ha adelantado, su estudio no puede separar la sustancialidad de los derechos garantizados de sus presupuestos procedimentales, toda vez que su finalidad se debe enmarcar, inexorablemente, dentro de una genuina jurisdicción constitucional de los derechos fundamentales. Así, dentro de esta lógica, es posible vislumbrar dos asuntos relevantes.

En primer término, la circunstancia de que el constituyente -en el artículo 20- intentó cerrar en un numerus clausus las situaciones jurídicas subjetivas que recibirán amparo mediante el recurso de protección, disponiendo que este alcanza a ciertos y determinados derechos fundamentales establecidos en el artículo 19, excluyendo aquellos derechos de contenido económico y social, como la educación y la seguridad social, o solo tutelando algunos parcialmente, como la salud y la libertad de trabajo; también se excluyen de la tutela de protección, el debido proceso, el principio de legalidad penal y la igualdad ante las cargas y cargos públicos. Circunstancia que puede explicarse en la propia estructura material y dogmática de la Carta, que en muchos aspectos es deficitaria en la esfera de los derechos fundamentales. En efecto, debido a la perspectiva ideológica que adhiere la Constitución, excluye de su texto importantes derechos sociales, y los que reconoce, son excluidos de la garantía jurisdiccional de protección o solo tutelados parcialmente. Asimismo, con la entrada en vigor del Código Procesal Penal, quedó en evidencia un importante déficit constitucional respecto a garantías de orden procesal; también se debe mencionar, el aún pendiente reconocimiento de los pueblos originarios, por dar algunos otros ejemplos.

Déficit que no deja de ser paradójico, pues nuestra democracia constitucional en vigor (a lo menos desde la perspectiva del ordenamiento jurídico que la sustenta) es, en términos generales, la más sustancial que se ha conocido en la historia republicana, pues el proceso de rematerialización de la actual Carta (muy cercana a la corriente del constitucionalismo y también del neoconstitucionalismo, como variante acentuada de aquel), le ha dado un fuerte contenido al Estado constitucional. Cuestión que, a la luz del constitucionalismo democrático, pone en evidencia la necesidad de alcanzar las condiciones de realización constitucional óptimas, a fin de revalidar el actual cometido sustancial de la Constitución.

En segundo lugar, hay que hacer mención a la estrecha conexión que debiera plasmarse en el razonamiento judicial de los jueces de protección, con la perspectiva constitucional que trazan los derechos subjetivos tutela- 
dos. Dicho en otras palabras, el especial telos de tutela judicial efectiva de los derechos fundamentales de esta acción constitucional, debiera circunscribir inexorablemente el razonamiento de los jueces de protección.

Queda abierta la cuestión, de no fácil solución, relativa a la delimitación de los derechos fundamentales cuando concurren la Constitución y las leyes a regularlos, particularmente si se busca determinar el parámetro de juridicidad que tendrá que enfrentarse el juez de protección, para resolver esta temática que, en última instancia, siempre involucra la tutela de un específico derecho fundamental.

Se debe seguir ahondando en este último tópico, sobre todo si la acción de protección juega un destacado rol en el ya mencionado proyecto de ley de acciones protectoras de derechos. Si nos centramos en el referido proyecto, en su artículo 45, referente a la "Naturaleza y objeto del recurso de protección", se reproduce textualmente el artículo 20 de la Carta Fundamental, incorporando a esta iniciativa legal -como no podría ser de otro modo- los aspectos sustanciales y de procedimiento contenidos en la regulación constitucional. Modificando, eso sí, en varios aspectos, la reglamentación del Auto Acordado de la Corte Suprema; este último, no obstante, receptó varios de tales cambios en su modificación de 2007, sobre todo en lo concerniente a los requisitos de admisibilidad.

El proyecto de ley que se reseńa, en su artículo 47, relativo a la "Legitimación procesal activa”, establece que podrá interponer el recurso de protección, cualquier persona afectada ilegal o arbitrariamente en el legítimo ejercicio de sus derechos fundamentales, es decir, mantiene los presupuestos de contrariedad a Derecho, tanto de ilegalidad como de arbitrariedad, que agravien un derecho fundamental.

Si focalizamos nuestro análisis en el presupuesto de "ilegalidad" de la acción de protección, la duda que surge es la siguiente: ¿̨resulta realmente posible, dentro de la unidad que sustenta a todo ordenamiento jurídico, especialmente en materia de derechos fundamentales, considerar como ámbitos separados la legalidad ordinaria y la legalidad constitucional? Para responder esta duda, hay que partir de la base que el control jurídico que se lleva a cabo por el tribunal de protección, no puede ser otro que un control concreto de constitucionalidad. Ya que lo que caracteriza a un orden jurisdiccional es la naturaleza de las normas que fundan las pretensiones que ante él se deducen y que el respectivo órgano jurisdiccional, en consecuencia, ha de aplicar. En el caso de la acción de protección, y teniendo en cuenta la amplia gama de pretensiones que se pueden hacer valer, la tutela judicial debe restablecer el imperio del Derecho, frente a un agravio que produce la privación, perturbación o amenaza en el legítimo ejercicio de un derecho fundamental.

En el plano del amparo de los derechos fundamentales, difícil resulta considerar como ámbitos separados las cuestiones de constitucionalidad y los asuntos de estricta legalidad, especialmente si en el caso de la juris- 
dicción de protección, solo a los Tribunales Superiores de Justicia les toca resolver la cuestión. En este contexto, estimamos que se debería lograr una integración en los contenidos del razonamiento, toda vez que el juzgamiento de la legalidad ordinaria solo tiene asidero cuando esté en juego la tutela de un derecho fundamental susceptible de protección, poniendo en evidencia la realidad interrelacionada, especialmente en materia de derechos fundamentales, entre legalidad ordinaria y legalidad constitucional. Conclusión que se ve reforzada en el ordenamiento constitucional chileno, con la existencia de una reserva general de ley en la regulación de los derechos fundamentales (artículo $63 \mathrm{~N}^{\circ} 2$ y 20 , y artículo $19 \mathrm{~N}^{\circ} 26$ ), existiendo una verdadera colaboración entre normas constitucionales y legales.

Ahora bien, sostiene Gómez -haciendo referencia a los presupuestos de la acción de protección-, que "la lesión ha de provenir de un "acto u omisión" que revista la particularidad de ser, además de inconstitucional por lesionar tales derechos [fundamentales], "ilegal o arbitraria"27. Y agrega este autor, que "la clave de la protección es la tutela de un derecho fundamental lesionado en una dimensión subjetiva de este, vale decir, solo si la posición del individuo agraviado se encuentra amparada por un derecho fundamental" 28; por ello, "al acoger un recurso de protección -indica- se ampara a un individuo en la situación o posición subjetiva en que se encuentra. Pero - prosigue- para formular esa decisión ha debido interpretarse o reconstruirse un derecho fundamental de manera de establecer si la situación queda o no cubierta y si es amparable. No solo los hechos deben ser comprendidos y por lo mismo interpretados por los jueces constitucionales (para efectos del recurso de protección lo son), también el proceso de subsumir el caso en un enunciado de la Carta exige al juez que reconstruya e interprete el derecho [técnica de ponderación] para establecer si la acción o la omisión está amparada o es contraria a él. Este acto de aplicación -se dice por último-, y al mismo tiempo de interpretación y reconstrucción por el Derecho, define una posición que cualquier ciudadano puede esgrimir ante la jurisdicción" ${ }^{29}$. Dicho en otros términos, este proceso de subsunción-ponderación que busca resolver la problemática de un determinado derecho fundamental, se debe enmarcar dentro de una argumentación guiada por parámetro de la constitucionalidad que fijan los derechos fundamentales; cuestión que no solo tiene una dimensión privada, sino también pública, ya que subyace en esta decisión un imperativo constitucional de "igual" protección en el ejercicio de los derechos de $\operatorname{todos}^{30}$.

Gómez, G. (2005). Derechos fundamentales y recurso de protección. Santiago: Ediciones Universidad Diego Portales, p. 19.

Gómez (2005) 19.

Gómez (2005) 21.

Gómez (2005) 21. 
Claramente, en la esfera de la acción de protección, se despliega la jurisdicción constitucional, extraordinaria y con un ámbito específico de tutela, diferente a la jurisdicción ordinaria o común. Se busca, en consecuencia, de esta acción tutelar de derechos, generar una auténtica jurisprudencia constitucional, cuyas resoluciones, que encarnan la tutela judicial efectiva y exclusiva de los derechos fundamentales agraviados, produzcan el efecto de cosa juzgada material.

Es decir, la sede jurisdiccional exclusiva para discutir la temática de los derechos fundamentales es la instancia de protección, que encarna una forma de cognición limitada o específica en tal materia; de ahí que posea una especial fuerza vinculante, de cosa juzgada material, la parte de la sentencia de protección referida a los aspectos de derechos y libertades fundamentales que ampara el artículo 20. Cualquier otra pretensión no conexa con este tema deberá ser planteada en un proceso ordinario. Por esta razón sería criticable el artículo 64, del proyecto de ley, que expresa que "la sentencia firme de protección producirá efectos de cosa juzgada formal respecto al derecho o garantía objeto del proceso". Con ello se incentivaría la tendencia a considerar el recurso de protección como un equivalente jurisdiccional, asimilándolo a los procedimientos comunes, cuya consecuencia se traduce en debilitar el debate constitucional e incentivar, por ende, el alto contenido de legalidad que presentan los problemas que se conocen. Asunto que es incrementado, principalmente, por el presupuesto de "ilegalidad" que exige el constituyente para su interposición.

Se coincide con Gómez, en el sentido de que "el recurso de protección fue mal diseñado, pues no ha logrado clarificar si es un equivalente o sustituto procesal de las acciones que prevé el ordenamiento común legalmente o si es una acción constitucional para la tutela de derechos. Esta indefinición es atribuible a una confusa concepción de quienes la crearon"31. Vaguedad que, en nuestra opinión, habría que encontrar en el propio origen del este recurso, que, como algo se ha adelantado, está estrechamente relacionado con la carencia de una jurisdicción contencioso-administrativa dentro del sistema orgánico de control jurídico que configuraba la Carta de 1925, y con la necesidad de potenciar por parte de la jurisdicción ordinaria el control de la actividad jurídica del Jefe del Estado, especialmente frente a actos u omisiones "arbitrarios" o "ilegales". Presupuestos que calzan, respectivamente, con las potestades discrecionales o regladas de la Administración.

Creemos sinceramente que este hecho ha estigmatizado el recurso de protección, transformándolo en un verdadero equivalente o sustituto de la falta de una jurisdicción especializada en lo contencioso-administrativo, en donde los administrados, por medio de la utilización de subterfu- 
gios argumentativos, han contribuido a su desperfilamiento y expansión, conociendo muchas veces de temáticas vinculadas a derechos o intereses legítimos no fundamentales. Todo lo cual incentivado por la ilimitadas pretensiones que pueden hacer valer los recurrentes, más aún cuando se habilita al Tribunal para disponer de todas las medidas que estime necesarias para restablecer el imperio del Derecho y proteger a los afectados por acto u omisión arbitrario o ilegal.

A esta altura de la exposición y teniendo en cuenta la relación de sustancialidad y procedimentalidad con que se ha analizado esta garantía jurisdiccional, la pregunta que surge por sí sola es la siguiente: ¿en lo que respecta al recurso de protección, el proyecto de ley en comento ha perfeccionado realmente este instituto procesal?

Sin duda que hay aspectos que apuntan en este sentido, como, por ejemplo, el aumento de plazo para su interposición (artículo 48) o la exigencia de admisibilidad de "si persigue fundadamente la tutela de un derecho fundamental protegido por esta vía procesal", conectando de mejor modo el agravio con el amparo de un específico derecho fundamental y posibilitando, frente a una resolución que declare la inadmisibilidad, la interposición de los recursos de reposición y apelación en subsidio (artículo 51). No obstante, a la luz de lo expresado anteriormente, se cree que son insuficientes, y que no permitirían encauzar el razonamiento judicial con el parámetro de una auténtica jurisdicción constitucional, que es, precisamente, la gran carencia de la actual configuración del proceso de protección, cuya argumentación se vincula principalmente a lo meramente legal (de escasa significación constitucional cuando se impugnan actos emanados del Estado y frente a actos de los particulares el recurso de asemeja a una acción cautelar que evita el daño o corrige la autotute$\mathrm{la}^{32}$ ), omitiendo muchas veces las cuestiones de constitucionalidad más conectadas con los derechos fundamentales.

Uno de los aspectos que, a nuestro juicio, incentivaría tal distorsión argumentativa, habría que encontrarla en los presupuestos procesales de "ilegalidad" y "arbitrariedad", cuyo despliegue, en muchos casos, genera una deficiencia estructural en el amparo de esta garantía jurisdiccional, y ello se superaría eliminando tales presupuestos procesales. Con ello se pretende consolidar un control de constitucionalidad lo más puro posible del acto u omisión que se verifica, reconduciendo, asimismo, la vinculación de los jueces de protección con el ordenamiento jurídico, dado el especial telos de tutela de los derechos fundamentales de esta acción constitucional. Cuya verificación no debe perder de vista el parámetro de la perspectiva constitucional de los derechos fundamentales, lo incluye el conocimiento tanto de las cuestiones de mera legalidad como las cuestio- 
nes de trascendencia constitucional. Expresado en otros términos, de esta forma el razonamiento judicial empleado por los jueces de protección se debe traducir en una decisión jurídica razonable, esto es, aquella decisión jurídica susceptible de ser justificada razonable y coherentemente con el ordenamiento constitucional, con el consecuente abandono en su argumentación de cualquier atisbo de positivismo legalista. Todo lo cual, con la finalidad de generar una genuina jurisdicción constitucional.

Lo expresado hasta ahora es posible sistematizarlo desde una triple perspectiva: críticas sustanciales, críticas procesales y las consecuencias que se derivan de estas falencias que, como veremos, es posible verificar en específicos períodos de desarrollo jurisprudencial. Cuestiones que a continuación pasamos a desarrollar.

\section{(2.2) CRÍticas SUSTANCIALES}

\section{(2.2.1) La naturaleza jurídica del "recurso de protección"}

Ya se ha destacado con anterioridad que el llamado recurso de protección es, en realidad, una acción de rango constitucional dado que se cumplen en ella todos los supuestos de ese instituto; y dicha afirmación proviene de su configuración y caracteres, más allá de su denominación ${ }^{33}$. $\mathrm{Al}$ respecto, De la Oliva, ha dicho que la acción "sería, pues, el derecho a una concreta tutela jurisdiccional dirigido frente al Estado -el tribunal no es sino un órgano del Estado- y respecto de un adversario, derecho cuya satisfacción consiste en la sentencia que concede dicha tutela concreta al actor" 34 . Por tanto, al contrastar dicho instrumento con el concepto más autorizado recién indicado cumple con las condiciones para que se le reconozca claramente tal sentido.

Y como igualmente bien se sabe, esta es la vía procesal que tiene por objeto restablecer el imperio del Derecho y asegurar la debida protección del afectado por causa u omisiones arbitrarias o ilegales en cuya virtud se sufra privación, perturbación o amenaza en el legítimo ejercicio de derechos fundamentales y que sean amparables por esta vía.

Dadas las dos afirmaciones precedentes, y del mismo modo que postula Bordali ${ }^{35}$, el ejercicio de esta acción supone la puesta en marcha de un verdadero proceso de protección toda vez que hay un conflicto entre

33 Se consigna por Tavolari que alguna doctrina minoritaria sostenía que se trataba de un recurso, "sin entregar una sola fundamentación que no fuera el número de veces que se utiliza la expresión 'recurso'". TAVOLARI (1994) 187, nota 26.

34 De la Oliva Santos, A. (1980). Sobre el derecho a la tutela jurisdiccional. La persona ante la Administración de Justicia: derechos básicos. Barcelona: Bosch, p. 16.

35 Bordalí Salamanca, A. (1999). "El proceso de protección". Revista de Derecho Universidad Austral de Chile. Vol. V, pp. 49-53; y Él mismo (2003) Temas de Derecho Procesal Constitucional. Santiago: Universidad Austral de Chile-Editorial Fallos del Mes, pp. 119-129. 
partes, que conoce un tribunal determinado por una competencia legal y previa, encaminado a la tutela de derechos fundamentales, y cuyas sentencias producen cosa juzgada, formal o material. Este es un aspecto insoslayable si es que se considera que las actividades que se realizan a propósito del ejercicio del requerimiento de protección de algún o algunos derechos fundamentales por parte de los tribunales, es ejercicio de jurisdicción; pues esta solo se desarrolla dentro de un proceso, como sería el caso.

Claro es que, hay que reconocer, este proceso tiene varias complejidades las que emanan de sus especiales características. Y precisamente esos especiales caracteres en realidad lo configuran como un proceso sumario especial o sumario interdictal ${ }^{36}$, y no como un proceso cautelar autónomo.

Obviamente esta oscuridad en torno a su naturaleza jurídica, repercute claramente en la fuerza de las sentencias dictadas, lo que constituye un aspecto sustantivo relevantísimo para los justiciables.

\section{(2.2.2) Propietarización y vulgarización}

El término, acuñado por Vergara Blanco hace más de una década ${ }^{37}$, alude a una fenómeno producido fundamentalmente a partir de la vuelta a la democracia y que se ha ido acrecentando con el correr de los años. En aquel se realizan afirmaciones que guardan plena vigencia y han aumentado su gravedad, como el hecho que fundamentalmente por la vía de la invocación del "derecho de propiedad" del artículo 19 numeral 24 y del "derecho a la igualdad" del artículo 19 numero 2, se haya abierto a todos los derechos fundamentales y no estrictamente a los garantizados del artículo 20 y que por medio de esa misma vía se hayan protegido posiciones o situaciones subjetivas, como meras expectativas, que bajo supuesto alguno constituyen derechos fundamentales ${ }^{38}$.

Adicionalmente en virtud de lo anterior, nuestro Derecho se ha ido progresivamente "vulgarizando" 39 , especialmente -en lo que interesa a este estudio- a partir del escaso aporte dogmático en la configuración del contenido sustantivo de los derechos fundamentales producto de la zigzagueante jurisprudencia que se ha desarrollado en relación a este instituto. En efecto, ni por medio de la Constitución, ni de la ley se ha dotado de

BORDALí (2003) 152-156. Lo que posteriormente repite y amplía para señalar que en algunos casos el recurso de protección puede considerarse un proceso cautelar en casos de tutela urgente de derechos fundamentales aunque sujeto a varias condiciones y limitaciones. Él mismo (2006a) "El Recurso de Protección como proceso de urgencia". Revista Chilena de Derecho. Vol. 31 No 2, pp. 281-287. cho. Universidad Católica de Valparaiso. XIV, pp. 281-291.

38 VERGARA (1991-1992) 289.

39 Bordalí Salamanca, A. (2006b). "El Recurso de Protección entre exigencias de urgencia y seguridad jurídica". Revista de Derecho. Universidad Austral de Chile. Volumen XIX No 2, p. 206, 
contenido sustantivo a los derechos fundamentales, por lo que dicha tarea ha recaído en la jurisprudencia que muy escasos aportes ha realizado al respecto como ya se ha destacado, pues tanta jurisprudencia puede encontrarse en un sentido como en otro, abierto precisamente a todas las posibilidades de un "público" que utiliza a su amańo este instrumento ${ }^{40}$. Como consecuencia de ello, citando a Aldunate, "el resultado es un notable empobrecimiento conceptual en el ámbito de los derechos fundamentales constitucionales, que si bien alcanza sus extremos en el caso del derecho de propiedad sobre bienes incorporales, se extiende también a otros derechos amparados por la protección, y a casi todos los tópicos atinentes a los derechos fundamentales" 41 .

\section{(2.3) CRÍticas PRocesales}

\section{(2.3.1) Admisibilidad del recurso}

Como bien afirma Yáñez ${ }^{42}$, no existe en el texto de la Constitución condiciones de admisibilidad formal del recurso. Es más, se consideró siempre que este debía estar exento de formas con miras de dar la más eficaz y eficiente respuesta por parte de las Cortes a los justiciables.

Sin embargo, tanto del auto acordado de Corte Suprema de 2 de abril de 1977, el de 27 de junio de 1992 y sobre todo la modificación de 4 de mayo de 1998, ratificado por la reforma de 25 de mayo de $2007^{43}$, establecen requisitos de admisibilidad formal que no se conectan con el carácter informal, tanto que puede declararse inadmisible por la sala que conoce en cuenta de este primer examen del mismo sin entrar a una análisis de fondo del asunto. Es decir, sin verificar la efectividad o no de haberse violado derechos fundamentales con las graves consecuencias que derivan de esto

Adicionalmente, el control de la admisibilidad de las pretensiones de la protección impetrada, ocurre en abierta contradicción con el derecho a la tutela judicial efectiva consagrada en la Constitución si bien no de manera explícita como tal, implícitamente puede deducirse del artículo 7, 19 No 3, 20, 21, 76 y 82 de la Constitución. En este sentido Aldunate resume muy bien este complicado panorama, al señalar lo siguiente: "Al admitirse sin mayores contenciones, la acción ha sobrepasado la capacidad de respuesta de tribunales $y$, a la ya evidente inconstitucionalidad de

\footnotetext{
40 Para lo cual pueden verse los extensos listados relativos a la jurisprudencia habida sobre derechos fundamentales, presentados en Gómez (2005) 603-657.

41 Aldunate Lizana, E. (2008). Derechos Fundamentales. Santiago: Legal Publishing, p. 365.

42 Yáńez Ramírez, R. (1997). "Sobre la involución del recurso de protección". Revista de Derecho. Universidad de Concepción. No 202, ańo LXV, pp. 122-125.

43 Publicado en el Diario Oficial el 8 de junio de 2007.
} 
la regulación de su tramitación por auto acordado de la Corte Suprema se ha agregado la modificación de dicha tramitación en términos de incorporar un examen de admisibilidad, que deja en manos de la respectiva corte de apelaciones un amplio margen de discrecionalidad para acoger o rechazar las acciones impetradas. En efecto, desde 1998 y hasta el ańo 2007, el examen de admisibilidad exigía que la acción estuviese someramente fundada. Sin embargo -prosigue-, ante un universo de absoluta dispersión conceptual en materia de derechos fundamentales, la propia exigencia de fundamento somero se torna vaga. A partir del ańo 2007 se vuelve a modificar esta exigencia, reduciéndose al requisito de señalar "el hecho constitutivo de la lesión (...) la conclusión general, en todo caso, es unívoca; la reacción a la incontinencia del recurso de protección ha provocado un esclerosamiento de esta acción que termina por atentar contra su carácter de protección oportuna y expedita" ${ }^{4}$.

Del mismo modo, agrava esta situación la circunstancia de que en este juicio de admisibilidad está implícito, nada menos, que la posibilidad de ejercer o no el derecho constitucional a la acción o a la tutela jurisdiccional, que asegura la Carta Fundamental en el artículo $19 \mathrm{~N}^{\circ} 3$ inciso $1^{\circ}$, y que reafirma el propio Auto Acordado de la Excma. Corte Suprema, al considerar esta vía de amparo "como una acción jurídica de real eficacia para la necesaria y adecuada protección de los derechos y garantías individuales sujetas a la tutela de este medio de protección". Dicho en otros términos, en la apreciación formal de admisibilidad que hacen las Cortes de Apelaciones, también está implícita la tutela de derechos fundamentales (en este caso, el acceso a la justicia), cuestión que es más apremiante en sede de protección, ya que, precisamente, se trata de una instancia especial de amparo de tales derechos esenciales, debiéndose siempre privilegiar una interpretación favorable a su conocimiento y pronunciamiento.

Ante todo, se debiera anteponer la protección constitucional y el deber estatal de garantizar, efectivamente, los derechos fundamentales de acuerdo con los artículos $1^{\circ}, 5^{\circ}$ inciso $2^{\circ}$ y $19 \mathrm{~N}^{\circ} 26$, y artículo 20 de la Constitución, sistemática y teológicamente armonizados con los artícu$\operatorname{los} 1^{\circ}, 2^{\circ}, 8^{\circ}$ y $25^{\circ}$ de la Convención Americana de Derechos Humanos. Especial énfasis se debe dar a este último artículo de la Convención Americana (artículo 25.1), ya que establece el derecho de toda persona a un "recurso efectivo, sencillo y rápido", para que ampare sobre todo actos que violen sus derechos fundamentales reconocidos por la Constitución ${ }^{45}$. Dentro de este contexto, inexorablemente, se debe circunscribir la acción de protección, como una vía rápida, eficaz e informal, que permita un ac-

Nogueira Alcalá, H. (2008). Derechos fundamentales y garantias constitucionales. Tomo I. Santiago: Librotecnia, pp. 321-325. 
ceso rápido a la justicia y no constituir un obstáculo para acceder a ella y, por ende, solicitar su tutela jurisdiccional.

\section{(2.3.2) Debido proceso en el "recurso de protección"}

La cuestión en torno a la exigencia de un debido proceso o de un proceso racional y justo, precisamente en la tramitación del recurso de protección de garantías constitucionales es de aquellas condiciones básicas de garantía de las mismas. En efecto, este proceso debe cumplir con esas condiciones so pena de darse el contrasentido que se vulneren derechos fundamentales por falta de resguardo de esas condiciones, precisamente en este proceso tutelador.

El proceso, en general, se ha caracterizado como una instancia de decisión por un tercero dotado de desinterés objetivo-noción comprensiva de la independencia e imparcialidad-; de carácter contradictoria; en donde existe la posibilidad igualitaria de allegar antecedentes probatorios en defensa de sus pretensiones; y que las decisiones del órgano jurisdiccional produzcan cosa juzgada. Precisamente a este proceso se refiere el artículo 19 No 3 inciso 5 de la Constitución.

Pues bien, ¿̨el proceso del "recurso de protección" cumple con esas condiciones?

Creemos que no, y fundamentalmente por la escasa posibilidad de contradictoriedad -la que se reduce al "informe" pedido a la contraparte-, y en la escasa posibilidad de aportación de prueba tanto a la "parte recurrente" como al "recurrido".

Las anteriores falencias, y que han sido puestas en relevancia en más de una oportunidad ${ }^{46}$, constituyen un despropósito jurídico y requiere una solución, sea por vía de un complemento legal de protección de derechos fundamentales, sea por vía de dotar efectivamente a nuestro Derecho de un proceso administrativo, o ambas, en cuya virtud se protejan efectivamente los derechos fundamentales.

\section{(2.4) CONSECUENCIAS DE ESTAS FALENCIAS}

Producto de lo anterior se ha producido una importante disminución del ámbito de resguardo de los derechos fundamentales.

Consecuencia directa de ello es el cuadro que se exhibe enseguida relativo a un análisis estadístico del proceso de protección en la Corte de Apelaciones de La Serena durante el período 2001 a 2005.

\footnotetext{
46 Bordalí (1999) 56-58; Bordalí Salamanca, A. / Ferrada Bórquez, J.C. (2004). "El recurso de protección como proceso urgente de tutela de derechos fundamentales". La Semana Juridica $\mathrm{N}^{\circ} 201$, p. 14.
} 


\section{(2.4.1) Cuadro de situación general}

\begin{tabular}{|c|c|c|c|}
\hline Ańos & $\begin{array}{c}\text { Total de causas } \\
\text { ingresadas }^{47}\end{array}$ & $\begin{array}{c}\text { Recursos de Protección } \\
\text { ingresados }\end{array}$ & $\begin{array}{c}\text { Porcentaje del } \\
\text { Total }\end{array}$ \\
\hline 2001 & 41.502 & 121 & 0,29 \\
\hline 2002 & 60.204 & 119 & 0,21 \\
\hline 2003 & 61.716 & 108 & 0,17 \\
\hline 2004 & 61.138 & 97 & 0,15 \\
\hline 2005 & 61.897 & 80 & 0,12 \\
\hline TOTAL & 286.457 & 525 & 0,18 \\
\hline
\end{tabular}

\section{(2.4.2) Cuadro de causas ingresadas y falladas}

\begin{tabular}{|c|c|c|c|c|c|}
\hline \multirow{2}{*}{ Años } & Causas & \multicolumn{4}{|c|}{ Causas falladas } \\
\cline { 3 - 6 } & ingresadas & Aceptadas & Rechazadas & Otros Motivos & Total \\
\hline 2001 & 121 & 26 & 82 & N/A & 108 \\
\hline 2002 & 119 & 25 & 106 & N/A & 131 \\
\hline 2003 & 108 & 25 & 41 & 30 & 96 \\
\hline 2004 & 97 & 15 & 53 & 34 & 102 \\
\hline 2005 & 80 & 12 & 45 & 19 & 76 \\
\hline TOTAL & 525 & 103 & 327 & 83 & 513 \\
\hline
\end{tabular}

\section{(2.4.3) Cuadro de porcentajes de causas aceptadas y rechazadas, en relación al total de causas falladas}

\begin{tabular}{|c|c|c|c|c|c|c|c|}
\hline Años & $\begin{array}{c}\text { Acep- } \\
\text { tadas }\end{array}$ & $\%$ & $\begin{array}{c}\text { Recha- } \\
\text { zadas }\end{array}$ & $\begin{array}{c}\text { Otros } \\
\text { motivos }\end{array}$ & $\begin{array}{c}\text { Rechazadas }+ \\
\text { O. Motivos }\end{array}$ & $\%$ & $\begin{array}{c}\text { Total de } \\
\text { causas falladas }\end{array}$ \\
\hline 2001 & 26 & 24 & 82 & N/A & 82 & 76 & 108 \\
\hline 2002 & 25 & 19 & 106 & N/A & 106 & 81 & 131 \\
\hline 2003 & 25 & 27 & 41 & 30 & 71 & 73 & 96 \\
\hline 2004 & 15 & 15 & 53 & 34 & 87 & 85 & 102 \\
\hline 2005 & 12 & 16 & 45 & 19 & 64 & 76 & 76 \\
\hline TOTAL & 103 & 20 & 327 & 83 & 410 & 80 & 513 \\
\hline
\end{tabular}

Información obtenida en www. poderjudicial.cl. Se incluyen causas civiles, penales y laborales. Información obtenida a través la Corporación Administrativa del Poder Judicial.

Es importante indicar, que a partir del 2003 cambia la forma de clasificar la acción de protección, pues antes de esa fecha, en las "Rechazadas" se incluían las inadmisibles, las desistidas, archivadas o devueltas, etc. 


\section{(2.4.4) Cuadro de intervinientes ${ }^{50}$}

\begin{tabular}{|l|c|c|c|c|c|c|}
\hline Años & $\begin{array}{c}\text { Conflicto } \\
\text { entre } \\
\text { particulares }\end{array}$ & $\%$ & $\begin{array}{c}\text { Conflicto } \\
\text { con algún } \\
\text { miembro de la } \\
\text { Administración } \\
\text { del Estado } 51\end{array}$ & $\%$ & $\begin{array}{c}\text { Conflicto entre } \\
\text { miembros de la } \\
\text { Administración } \\
\text { del Estado }\end{array}$ & $\%$ \\
\hline 2001 & 42 & 46 & 49 & 54 & - & - \\
\hline 2002 & 58 & 63 & 32 & 35 & 1 & 2 \\
\hline 2003 & 36 & 47 & 29 & 51 & 1 & 2 \\
\hline 2004 & 50 & 59 & 35 & 41 & - & - \\
\hline 2005 & 46 & 63 & 27 & 37 & - & - \\
\hline TOTAL & 232 & 57 & 172 & 42 & 2 & 1 \\
\hline
\end{tabular}

\section{(2.4.5) Cuadro de derechos más reclamados (número de veces) $)^{52}$}

\begin{tabular}{|l|c|c|c|c|c|}
\hline Derechos & 2001 & 2002 & 2003 & 2004 & 2005 \\
\hline Derecho de Propiedad & 47 & 53 & 48 & 48 & 44 \\
\hline Igualdad ante la Ley & 15 & 16 & 26 & 15 & 11 \\
\hline Igualdad ante la Justicia & 15 & 12 & 14 & 13 & 11 \\
\hline Derecho a la vida & 18 & 13 & 8 & 11 & 13 \\
\hline $\begin{array}{l}\text { Libertad de iniciar cualquier } \\
\text { actividad económica }\end{array}$ & 16 & 19 & 18 & 15 & 16 \\
\hline
\end{tabular}

La situación así descrita y figurada, puede repetirse en otras Cortes. En efecto, ya antes Yánez ${ }^{53}$ explicaba que, igualmente que en el caso presentado entre un 15 y un $20 \%$ fue acogido y los demás o declarados inadmisible o rechazados con lo que el estándar de efectiva protección es evidentemente insuficiente.

\footnotetext{
50 Esta información se obtuvo de la revisión de los respectivos Libros Copiadores de Sentencia, por lo tanto no hay registros de las causas que son declaradas inadmisibles de plano.

51 Dentro de la Administración del Estado se incluye Servicios Públicos, Poder Judicial y Gendarmería de Chile.

52 Esta información se obtuvo de la revisión de los respectivos Libros Copiadores de Sentencia, por lo tanto no hay registros de las causas que son declaradas inadmisibles de plano, desistidas y aquellas que son archivadas y devueltas.

53 YáŃEZ (1997) 122.
} 
Esto, junto a criterios restrictivos de interpretación constitucional, las ya declaradas funestas consecuencias de la declaración de admisibilidad, el zigzagueo jurisprudencial en la admisibilidad de conocer por esta vía cuestiones complejas, y demás factores expuestos permiten afirmar una verdadera involución del recurso de protección ${ }^{54}$.

En resumidas cuentas, se puede colegir de este breve análisis estadístico que el recurso de protección mantiene su carácter de extraordinario, pues su porcentaje de ingreso es bajo en comparación al total de causas que recibe la Corte de Apelaciones. Lo que sí llama poderosamente la atención -teniendo en cuenta la excepcionalidad del mismo-, es el alto porcentaje de causas que no llegan a ser falladas por el Tribunal (en su mayoría declaradas inadmisibles, cuestión que, cabe recordar, también puede ser declarada en la sentencia definitiva), y dentro de los pocos procesos de protección en que hay sentencia, es muy bajo el porcentaje de recursos que son acogidos.

\section{CONCLUSIÓN GENERAL}

Del análisis realizado es posible concluir con respecto a la acción de protección que, por un lado, su claro origen como sustituto de la falta de un sistema de control represivo de la Administración (cuestión que desde ya tiende a desvirtuar su esfera de aplicación), y, por el otro, el excesivo apego de los operadores jurídicos en torno al razonamiento ius privatista, alejado, muchas veces, de la perspectiva constitucional (que es precisamente la esencia de los derechos fundamentales que se tutelan por esta acción); o a través de una interpretación extensiva que realizan de ciertos derechos fundamentales (v. gr., propiedad) que lleva, en diversas oportunidades, a amparar derechos subjetivos no fundamentales o meros intereses legítimos, conforman un panorama altamente desalentador en el desarrollo de esta acción constitucional. Cuyo efecto, sin lugar a dudas, irradia a las personas que pueden utilizar tal instancia jurisdiccional, ya sea de un modo inhibitorio, o, por el contrario, lo potencia anómalamente (como se demuestra con la utilización ordinaria que llevan a cabo algunos abogados, que simplistamente creen estar en presencia de "uno más" de los recursos jurisdiccionales que les brinda el ordenamiento jurídico), lo que trae como consecuencia una pobre doctrina jurisprudencial $\mathrm{y}$, añadidamente, una inacabada construcción teórica del propio recurso. Es decir, lo práctico se impondría -negativamente- a lo teórico. Todo lo cual, asimismo, incentivado por un deficiente marco regulatorio. 


\section{BIBLIOGRAFIA}

Aldunate Lizana, E. (2008). Derechos Fundamentales. Santiago: LegalPublishing.

Barrientos Grandón, J. (1992-1993). "La fiscalización de los actos de gobierno en le época indiana y su desaparición durante la RepúbliCa". REH-J, XV.

Bordalí Salamanca, A. (1999). "El proceso de protección". Revista de Derecho Universidad Austral de Chile. Vol V.

(2003). Temas de Derecho Procesal Constitucional. Santiago: Universidad Austral de Chile-Editorial Fallos del Mes.

(2006a). "El recurso de protección como proceso de urgencia". Revista Chilena de Derecho. Vol 31 No2.

(2006b). "El Recurso de Protección entre exigencias de urgencia y seguridad jurídica". Revista de Derecho. Universidad Austral de Chile. Volumen XIX No 2.

I Ferrada Bórquez, J.C. (2004). "El recurso de protección como proceso urgente de tutela de derechos fundamentales". La Semana Jurídica. № 201.

Bravo Lira, B. (1986). "Derechos políticos y civiles en España, Portugal y América Hispana. Apuntes para una historia por hacer". Revista de Derecho Público $\mathrm{No}_{\text {s. }}$ 39-40.

(1989). "Protección jurídica de los gobernados en el Nuevo mundo (1492-1992). Del absolutismo al constitucionalismo". RCHHD, No XVI.

(1996). Por la razón o la fuerza. El Estado de Derecho en la Historia de Chile. Santiago: Ediciones Universidad Católica de Chile.

(2006). El Juez entre el Derecho y la Ley: Estado de Derecho y Derecho del Estado en el mundo hispánico, siglos XVI a XXI. Santiago: LexisNexis.

Carrasco Durán, M. (2002). Los procesos para la tutela jurisdiccional de los derechos fundamentales. Madrid: Centro de Estudios Políticos y Constitucionales

Cassagne, J.C. (2005a). "Consideraciones sobre la justicia administrativa en Argentina y en otros países de Iberoamérica”. En González Pérez, J. / Cassagne, J.C. (2005) La justicia administrativa en Iberoamérica. Buenos Aires: LexisNexis Argentina.

(2005b). "El origen hispánico del sistema judicialista y de otras instituciones del Derecho público iberoamericano y comparado". En González Pérez, J. I Cassagne, J.C. (2005) La justicia administrativa en Iberoamérica. Buenos Aires: LexisNexis Argentina.

Cazor Aliste, K. (2002). La sumisión a Derecho de los actos y disposiciones del Presidente de la República. Tomo II. Santiago: Universidad Central de Chile. 
De la Oliva Santos, A. (1980). Sobre el derecho a la tutela jurisdiccional. La persona ante la Administración de Justicia: derechos básicos. Barcelona: Bosch.

Ferrada Bórquez, J.C. / Bordalí Salamanca, A. / Cazor Aliste, K. (2003). "El recurso de protección como mecanismo de control jurisdiccional ordinario de los actos administrativos: una respuesta inapropiada a un problema jurídico complejo". Revista de Derecho Universidad Austral de Chile. Vol. XIV.

Fiamma Olivares, G. (1986). "El régimen administrativo tutelado". Gaceta Jurídica, No 71.

García de Enterría, E. / Fernández, T.-R. (2001). Curso de Derecho Administrativo. Tomo II. Madrid: Civitas.

Gómez, G. (2005). Derechos fundamentales y recurso de protección. Santiago: Ediciones Universidad Diego Portales.

Herrera Valverde, J. (2007). "El control jurisdiccional de los actos gubernativos en indias en los siglos XVI y XVII". Ius Publicum No 18.

Nogueira Alcalá, H. (2008). Derechos fundamentales y garantías constitucionales. Tomo I. Santiago: Librotecnia.

Sánchez Bella, I. (1979). "Las Audiencias y el Gobierno de las Indias (siglos XVI y XVII). REH-J, No 2.

Soto Kloss, E. (1982). El recurso de protección. Doctrina, origenes y jurisprudencia. Santiago: Editorial Jurídica de Chile.

(2003). "La protección de los derechos de las personas, logros y penurias". Ius Publicum No 10.

Tavolari Oliveros, R. (1994). "Hacia la tutela eficaz de los derechos humanos por la jurisdicción: una perspectiva desde el Derecho chileno referida al habeas corpus". En El mismo. Tribunales, jurisdicción y proceso. Santiago: Editorial Jurídica de Chile.

Vergara Blanco, A. (1991-1992). "La propietarización de los derechos". Revista de Derecho. Universidad Católica de Valparaíso. XIV.

Yáńez Ramírez, R. (1997). "Sobre la involución del recurso de protección". Revista de Derecho. Universidad de Concepción. No 202, año LXV. 